\title{
Inner Mitochondrial Membrane
}

National Cancer Institute

\section{Source}

National Cancer Institute. Inner Mitochondrial Membrane. NCI Thesaurus. Code C13331.

The inner mitochondrial membrane encloses a fluid-filled matrix and is elaborately folded with shelf-like cristae projecting into the matrix. The components of electron transport chain are integral part of the inner membrane. 